\title{
As origens do conceito de assédio moral no trabalho
}

\author{
The origins of the concept of bullying at work
}

${ }^{1}$ Editor convidado. Membro do Conselho Editorial da RBSO. Professor no Departement d'Organisation et Ressources Humaines École des Sciences de la Gestion, Université du Québec à Montréal (UQAM), Montreal, Canadá.
"Assédio moral" é uma das inúmeras expressões utilizadas para nominar esse tipo de violência no trabalho, sendo esta consagrada em língua portuguesa. No entanto, em inglês, utilizam-se diferentes termos, algumas vezes tentando-se estabelecer diferenças entre eles, as quais, na verdade, não existem. Assim, vamos apresentar aqui alguns deles.

Brodsky (1976) utilizou o termo harassment emprestado do conceito de assédio sexual (sexual harassment), eliminando o caráter sexual e utilizando apenas o conceito de harassment, que em português traduzimos por assédio.

Em 1989, Leymann escreve seu primeiro livro utilizando a palavra mobbing. Trata-se de um livro em sueco, sem tradução (LEYMANN, 1989). Em 1993, ele publica originalmente em alemão o livro Mobbing: psychoterror am arbeitsplatz, traduzido e publicado em francês em 1996 (LEYMANN, 1996a) como Mobbing: La persécution au travail (Mobbing: a perseguição no trabalho). O autor escolhe este termo para distinguir esta forma de violência psicológica entre adultos (mobbing) e adolescentes (bullying). Neste sentido, o autor nos sugere "guardar a palavra bullying para atividades entre crianças e adolescentes na escola e reservar a palavra mobbing para o comportamento adulto" (LEYMANN, 1996b, p. 167). Nesta época, outras palavras encontradas na literatura de língua inglesa para designar o assédio moral eram harassment e psychological terror (terror psicológico).

Zapf e Leymann (1996), no prefácio de um número especial do European Journal of Work and Organizational Psychology, dedicado ao assédio moral, discutem a questão da terminologia e indicam que alguns autores utilizam o termo mobbing como sugerido por Leymann e que outros autores preferem utilizar o termo bullying e afirmam que, com relação ao sentido, não existem diferenças e que mobbing, bullying ou harassment são termos intercambiáveis.

No Reino Unido, o termo utilizado é bullying, a partir da obra seminal de Adams e Crawford (1992), Bullying at work: how to confront and overcome it, que o definiu como "críticas persistentes e abusos pessoais, em público ou em privado, que humilham e inferiorizam a pessoa que é o alvo destes gestos" (p. 3). Andrea Adams, jornalista inglesa, contribuiu para a divulgação e foi responsável pelas primeiras pesquisas sobre assédio e uma série de documentários na BBC que obtiveram um enorme sucesso. 
Na França, em 1998, Marie-France Hirigoyen publica: Harcèlement moral: la violence perverse au quotidien (HIRIGOYEN, 1998). Esse livro tem uma importância política muito grande, pois catalisou um movimento social determinante em torno dessa forma de violência no trabalho. A partir da história de vida de seus pacientes, a autora faz uma análise e coloca um nome nesse sofrimento: assédio moral. Um ano após a publicação desse livro, a França se dota de uma lei criminalizando essa forma de violência. O livro se torna um sucesso de vendas com mais de 550 mil copias vendidas só em francês, sendo traduzido em 27 línguas. A tradução para o português se fez como: Assédio moral: a violência perversa do cotidiano; e para o espanhol: El acoso moral: maltrato psicológico en la vida cotidiana.

Desta maneira, podemos observar que, historicamente, o conceito foi batizado com nomes diferentes em seus respectivos países. Em consequência, conforme a pesquisa foi se desenvolvendo em outros países, dependendo da fonte primária, a utilização destes diferentes nomes, que descrevem o mesmo fenômeno, foi se propagando.

Atualmente se observa uma convergência conceitual de toda essa nomenclatura e uma utilização cada vez mais frequente do termo bullying em língua inglesa. ${ }^{2}$ Em francês, harcèlement moral; em português, assédio moral; e em espanhol, acoso moral. Todos os termos denotando o mesmo fenômeno, como nos indicam Einarsen et al. (2003), segundo os quais a diferença na sua utilização é uma questão muito mais cultural do que conceitual. ${ }^{3}$

Finalmente, devemos ressaltar que o assédio moral é um processo multicausal com diferentes abordagens e análises que ora estão focalizadas no indivíduo, ora no contexto ou ainda em ambos, indivíduos e contexto. Não se trata de um viés, mas de métodos e abordagens diferentes. Assim, a abordagem psicológica será mais centrada sobre o indivíduo, enquanto uma abordagem sociológica será mais voltada para as relações sociais e o seu contexto. Mesmo assim, nas pesquisas sobre assédio moral, essa distinção, muitas vezes, é difícil e o melhor exemplo é a obra de Leymann, na qual o autor utiliza uma abordagem psicológica, mas incorporando o contexto organizacional, a organização do trabalho, não individualizando a questão.

Nas últimas décadas, a pesquisa sobre o assédio moral avançou muito, sobretudo em termos da compreensão de suas consequências para a saúde física e mental, de seus efeitos negativos para vítimas, testemunhas e organização. Seus antecedentes: mudanças organizacionais, tipos de lideranças, organização do trabalho. Einarsen et al. (2003) nos propõem o seguinte modelo teórico para pesquisas e gestão do assédio moral no trabalho (Figura 1).

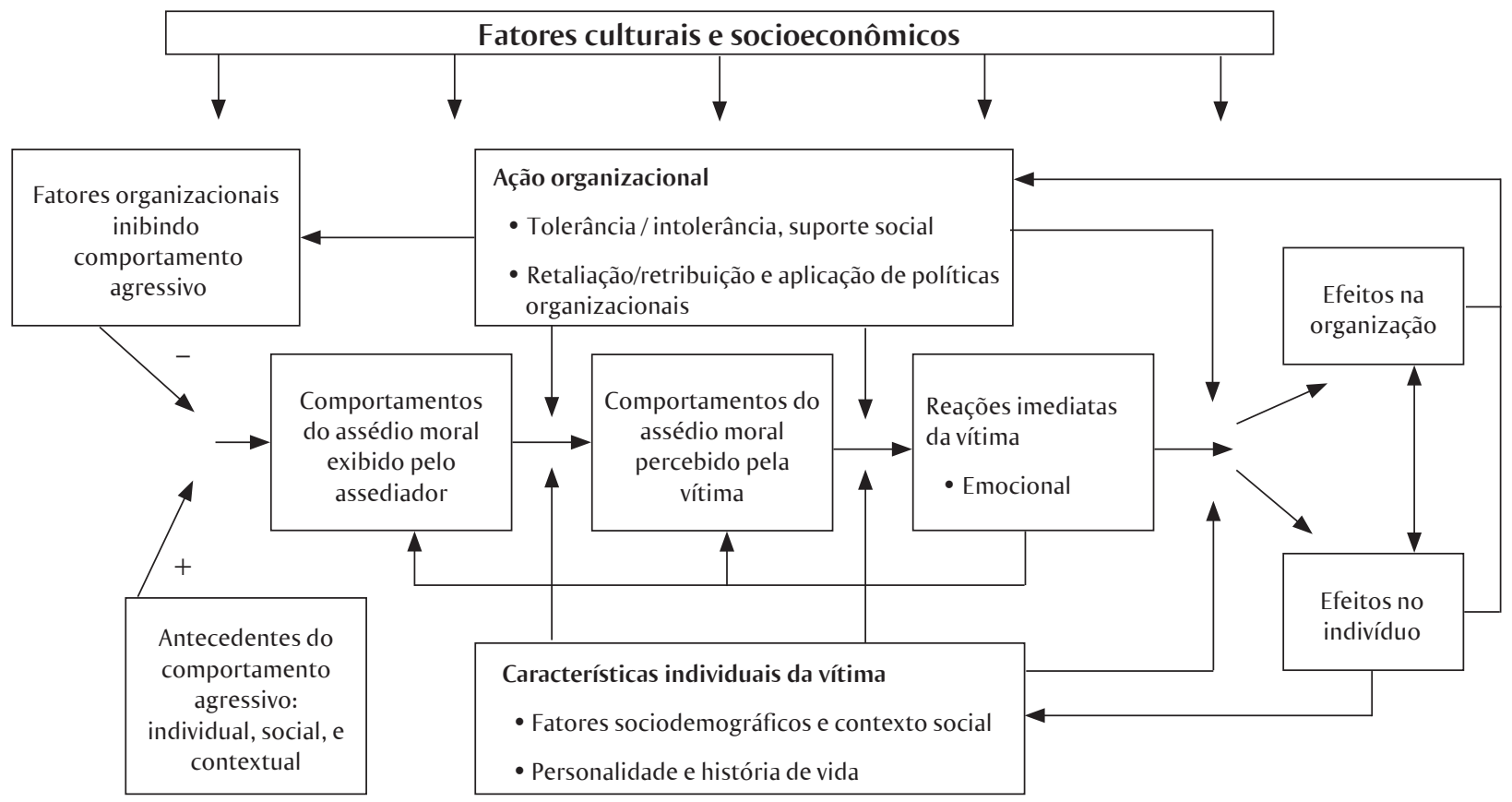

Fonte: Einarsen et al. (2003, p. 23)

Figura 1 Estrutura teórica para estudo e gestão do assédio moral no trabalho

\footnotetext{
${ }^{2}$ Ver Branch, Ramsay e Barker (2012)

${ }^{3}$ Ver também Di Martino, Hoel e Cooper (2003).
} 
Nesse modelo, os autores indicam as principais variáveis a serem consideradas em pesquisas, na gestão e nas intervenções de casos de assédio moral. Trata-se de uma primeira tentativa de propor um modelo teórico para a compreensão do assédio moral no trabalho integrando fatores individuais, da vítima e do agressor aos fatores organizacionais e socioeconômicos, assim como os antecedentes e as consequências do assédio moral para o indivíduo e para a organização.

Entretanto, apesar do desenvolvimento das pesquisas sobre assédio moral, alguns aspectos fundamentais ainda merecem nossa atenção e servem de pistas para pesquisas futuras. Em primeiro lugar, um modelo teórico compreensivo visando explicar essa forma de violência ainda resta ser desenvolvido. ${ }^{4}$

Outra pista para pesquisas futuras seria o desenvolvimento de estudos sobre os assediadores. Muito se fala acerca dos assediadores sem nenhum fundamento científico, pois nenhuma pesquisa foi realizada com eles. Assim, todo o saber que temos sobre esse ator importante na dinâmica do assédio moral foi construído através do olhar da vítima. Rayner e Cooper (2003) se referem à falta de pesquisas a respeito desse assunto como sendo o "buraco negro" nas pesquisas acerca do assédio moral.

Finalmente, resta ainda desenvolver pesquisas que possam avaliar a eficiência das estratégias de prevenção desta forma de violência no trabalho e de intervenção que têm sido implementadas nas organizações.

\section{Referências}

ADAMS, A.; CRAWFORD, N. Bullying at work - how to confront and overcome it. London: Virago, 1992.

BRANCH, S.; RAMSAY, S.; BARKER, M. Workplace bullying, bobbing and general harassment: a review. International Journal of Management Reviews, 2012. Article first published online: 6 jun 2012, DOI: 10.1111/j.1468-2370.2012.00339.x

BRODSKY, C. M. The harassed worker. Toronto: Lexington Books, 1976.

DI MARTINO, V.; HOEL, H.; COOPER, C. L. Preventing violence and harassment in the workplace. Dublin: European Foundation for the Improvement of Living and Working Conditions, 2003.

EINARSEN, S. et al. The concept of bullying at work. The european tradition. In: EINARSEN, S. et al. (Eds.). Bullying and emotional abuse in the workplace: international perspectives in research and practice. London: Taylor and Francis, 2003. p. xx-xx.
HIRIGOYEN, M.-F. Le harcèlement moral: la violence perverse au quotidien. Paris: Syros, 1998.

LEYMANN, H. Når Livet Slår Till. Stockholm: Natur \& Kultur, 1989.

. Mobbing: la persécution au travail. Paris: Éditions du Seuil, 1996a.

. The content and development of mobbing at work. European Journal of Work and Organizational Psychology, v. 5, n. 2, p. 165-184, 1996b.

RAYNER C.; COOPER, C. L. The black hole in bullying at work research. International Journal of Management and Decision Making, v. 4, n. 1, p. 47-64, 2003.

ZAPF, D.; LEYMANN, H. Foreword. European Journal of Work and Organizational Psychology, v. 5, n. 2, p. 161-164, 1996.

${ }^{4}$ Ver Branch, Ramsay e Barker (2012). 